\title{
Somatosensory evoked responses and central afferent conduction times in patients with multiple sclerosis
}

\author{
TROND GANES \\ From the Department of Neurology, Ullevål Hospital, Oslo, Norway
}

SUMMARY Evoked responses following median nerve stimulation were recorded from Erb's point, the cervical spine and the scalp and afferent conduction times between each recording point were determined in 44 patients with multiple sclerosis. A prolonged central conduction time was frequently the only finding in MS patients, particularly in the early stages of the disease. Changes in central conduction time thus seem to be more sensitive than changes either in response latencies or response morphology.

Cervical and cortical somatosensory evoked responses have proved of significant value to support the clinical diagnosis of multiple sclerosis. $^{1-9}$ The electrophysiological criteria generally used have been changes in amplitude, morphology and latencies of the responses. These parameters, however, vary from subject to subject and depend on several factors. ${ }^{810-15}$ In addition, inconclusive responses which cannot easily be classified as being either pathological or normal are encountered.

To overcome some of these problems several authors have tried to determine the central conduction time in the afferent somatosensory pathway. ${ }^{2312141617}$ The central conduction times are independent of the peripheral stimulation site and nerves in the arm, ${ }^{12} 13$ and varies little in healthy persons. ${ }^{12} 1417$

In the present study central conduction time was measured in patients with mutiple sclerosis. The median nerve was stimulated at the wrist and evoked responses recorded from the brachial plexus, cervical spine and scalp. Conduction times between each recording site were determined. The aim was to see if a slowing in the central impulse propagation occurred in patients with normal or inconclusive cervical and cortical evoked responses.

\section{Materials and methods}

The patients were 31 females and 13 males, the age

Address for reprint requests: Dr Trond Ganes, Dept of Clin Neurophysiol, Rikshospitalet, Oslo 1, Norway.

Accepted 20 June 1980 ranging from 19 to 61 years. The mean age was 35 years and the median age 33 years. The patients were classified according to McAlpine's clinical criteria ${ }^{18}$ as having possible, probable or definite multiple sclerosis. An additional group of five patients with suspected multiple sclerosis according to the criteria of McDonald and Halliday 19 also was included. The controls were taken from a previous study ${ }^{12}$ comprising 47 volunteer patients none of which had evidence of diseases affecting the centralo nervous system. This control group consisted of 22 males and 25 females, the age ranging from 16 to 70 years, mean and median age being 37 years. The control group was further divided in three subgroups each matching the corresponding patient group with respect to number, age and sex distribution (table 1).

Stimulation All patients were tested bilaterally using the median nerve at the wrist for stimulation using commercially available bipolar saddle electrodes. The stimuli were delivered by a Medelec constant isolated nerve stimulator. Stimulation frequency was $2 \mathrm{~Hz}$ and the strength was adjusted to produce a small muscular twitch in the thenar muscles.

Recording Conventional $9 \mathrm{~mm}$ silver disc EEG electrodes were used and fixed to the skin with Bentonite. The electrodes were placed midclavicularly (Erb's point), at the spine of the fifth cervical vertebra and contralateral over the hand area of the scalp. The common reference electrode was attached to the forehead. The signals were amplified, averaged and recorded on a conventional Medelec MS 6 EMG machine. High and low pass filters in the amplifiers were set to $16 \mathrm{~Hz}$ and $1.6 \mathrm{KHz}$ respectively in all channels. Sampling time was $40 \mathrm{~ms}$ for Erb and the cervical responses and $80 \mathrm{~ms}$ for the cortical response giving and A-D sampling rate of 26 and 13 points per ms respectively. The patients were sitting 948 
Table 1 A: Number, sex and age of patient and control groups. B: Mean response amplitudes of N9, N14 and N20 in each group

\begin{tabular}{|c|c|c|c|c|c|c|}
\hline & $\begin{array}{l}\text { Suspected and } \\
\text { possible MS }\end{array}$ & Control & Probable MS & Control & Definite $M S$ & Control \\
\hline $\begin{array}{l}\text { Female } \\
\text { Male } \\
\text { Median age } \\
\text { Age range }\end{array}$ & $\begin{array}{l}8 \\
4 \\
28 \\
19-48\end{array}$ & $\begin{array}{l}8 \\
3 \\
28 \\
18-48\end{array}$ & $\begin{array}{l}8 \\
4 \\
31 \\
21-54\end{array}$ & $\begin{array}{l}7 \\
5 \\
28 \\
18-58\end{array}$ & $\begin{array}{l}16 \\
4 \\
41 \\
27-61\end{array}$ & $\begin{array}{l}16 \\
4 \\
38 \\
28-68\end{array}$ \\
\hline & \multicolumn{2}{|l|}{ Amplitude $\mu V$} & \multicolumn{2}{|l|}{ Amplitude $\mu \mathrm{V}$} & \multicolumn{2}{|l|}{ Amplitude $\mu V$} \\
\hline & $\overrightarrow{X \pm S D}$ & $\overline{\bar{X} \pm S D}$ & $\bar{X} \pm S D$ & $\bar{X} \pm S D$ & $\bar{X} \pm S D$ & $\bar{X} \pm S D$ \\
\hline $\mathbf{N} 9$ & $\begin{array}{l}6 \cdot 5 \pm 1 \cdot 8 \\
r=24\end{array}$ & $7 \cdot 8 \pm 3 \cdot 9$ & $\begin{array}{l}8 \cdot 1 \pm 2 \cdot 3 \\
r=22\end{array}$ & $6 \cdot 1 \pm 4 \cdot 2$ & $\begin{array}{l}7 \cdot 2 \pm 3 \cdot 4 \\
r=40\end{array}$ & $6 \cdot 3 \pm 2 \cdot 9$ \\
\hline N 14 & $\begin{array}{l}2 \cdot 6 \pm 1 \\
r=24\end{array}$ & $3 \cdot 2 \pm 1 \cdot 2$ & $\begin{array}{l}2 \cdot 3 \pm 1 \cdot 1 \\
\mathrm{r}=21\end{array}$ & $2 \cdot 8 \pm 1 \cdot 2$ & $\begin{array}{l}1 \cdot 9 \pm 1 \cdot 4^{*} \\
r=29\end{array}$ & $2 \cdot 8 \pm 1 \cdot 2$ \\
\hline N 20 & $\begin{array}{l}1 \cdot 8 \pm 0 \cdot 9 \\
r=23\end{array}$ & $2 \cdot 5 \pm 0 \cdot 8$ & $\begin{array}{l}1 \cdot 3 \pm 0 \cdot 7^{*} \\
\mathrm{r}=17\end{array}$ & $2 \pm 0.6$ & $\begin{array}{l}1 \cdot 1 \pm 0 \cdot 6^{*} \\
r=28\end{array}$ & $2 \cdot 6 \pm 1 \cdot 9$ \\
\hline
\end{tabular}

*Indicates amplitude attenuation statistically different from the corresponding control values (Student's $t$ test, $\mathrm{p}<0 \cdot 01$ ).

" $r$ " denotes number of responses included in any one group.

relaxed in an arm chair or lying in a bed during the tests and care was taken to avoid tension in the neck muscles by supporting the head. ${ }^{10} 12$

The signal latencies were determined with an adjustable marker and were always measured from stimulus artifact to peak negativity of the responses. The amplitudes were measured from start of signal to peak negativity. Generally 150 analog signals from Erb's point and 300-600 analog signals from the cervical spine and scalp were averaged.

In the present study the $\mathrm{N} 9, \mathrm{~N} 14$ and $\mathrm{N} 20$ were used to denote the maximum negative peaks of the responses from Erb's point, the cervical spine and the scalp regardless of the actual latencies of the responses. The conduction time (CT) as measured between the peak latencies will be denoted N9-N14 and N14-N20 respectively.

\section{Results}

STATISTICAL EVALUATION OF RESPONSE DATA The response recorded over Erb's point (N9) was always present and of normal latency and amplitude in all but one of the patients examined. The cervical (N14) and cortical (N20) responses also were well preserved in many patients, even in some patients in the group with definite multiple sclerosis who were severely disabled. Subjective evaluation, however, left the impression that N14 and N20 amplitudes in the patients with apparently normal test results were somewhat reduced. Statistical comparisons of both amplitudes and latencies of the responses between the patients and the corresponding controls are shown in tables 1 and 2. Table 1 also illustrates the age distribution and sex of each patient and respective control groups. Since only well-preserved and easily recognisable responses were included, the number of responses varied and are denoted by the letter $r$ in tables 1 and 2. The data in table 1 confirmed that the amplitude of $\mathrm{N} 14$ and $\mathrm{N} 20$ were attenuated in patients with clinical probable and definite MS compared to those of the control groups

Table 2 Mean response latencies and afferent conduction times in each patient group and the corresponding control groups

\begin{tabular}{|c|c|c|c|c|c|c|}
\hline & $\begin{array}{l}\text { Suspected and } \\
\text { possible MS }\end{array}$ & Control & Probable MS & Control & Definite $M S$ & Control \\
\hline & \multicolumn{2}{|l|}{ Latency $(\mathrm{ms})$} & \multicolumn{2}{|l|}{$\overline{\text { Latency }(\mathrm{ms})}$} & \multicolumn{2}{|l|}{ Latency $(m s)$} \\
\hline & $\overline{\overline{X \pm S D}}$ & $\overline{X \pm S D}$ & $\bar{X} \pm S D$ & $\bar{X} \pm S D$ & $\overline{\bar{X} \pm S D}$ & $\bar{X} \pm S D$ \\
\hline N 9 & $\begin{array}{l}9 \cdot 7 \pm 0 \cdot 8 \\
r=24\end{array}$ & $9.8 \pm 0.9$ & $\begin{array}{l}10 \cdot 2 \pm 0 \cdot 8 \\
r=23\end{array}$ & $10 \pm 0.9$ & $\begin{array}{l}10 \pm 0 \cdot 8 \\
r=40\end{array}$ & $10 \pm 0.9$ \\
\hline N 14 & $\begin{array}{l}13 \cdot 1 \pm 1 \cdot 3 \\
r=24\end{array}$ & $13 \cdot 3 \pm 0 \cdot 9$ & $\begin{array}{l}13.6 \pm 0.9 \\
r=21\end{array}$ & $13 \cdot 5 \pm 1 \cdot 1$ & $\begin{array}{l}13 \cdot 3 \pm 2 \cdot 1 \\
r=29\end{array}$ & $13 \cdot 4 \pm 1$ \\
\hline \multirow[t]{2}{*}{ N 20} & $\begin{array}{l}18 \cdot 9 \pm 1 \cdot 4 \\
r=23\end{array}$ & $18 \cdot 9 \pm 1 \cdot 2$ & $\begin{array}{l}20 \cdot 2 \pm 1 \cdot 5 \\
r=17\end{array}$ & $19 \cdot 2 \pm 1 \cdot 4$ & $\begin{array}{l}21 \pm 2 \cdot 2^{*} \\
\mathrm{r}=28\end{array}$ & $19 \cdot 1 \pm 1 \cdot 2$ \\
\hline & \multicolumn{2}{|c|}{ Conduction time $(\mathrm{ms})$} & \multicolumn{2}{|c|}{ Conduction time (ms) } & \multicolumn{2}{|c|}{ Conduction time $(\mathrm{ms})$} \\
\hline N 9-N 14 & $\begin{array}{l}3.5 \pm 0.7 \\
r=24\end{array}$ & $3 \cdot 7 \pm 0 \cdot 7$ & $\begin{array}{l}3 \cdot 4 \pm 0.6 \\
r=21\end{array}$ & $3 \cdot 4 \pm 0 \cdot 6$ & $\begin{array}{l}3 \cdot 7 \pm 1 \cdot 1 \\
r=27\end{array}$ & $3 \cdot 4 \pm 0 \cdot 7$ \\
\hline N $14-\mathbf{N} 20$ & $\begin{array}{l}5 \cdot 6 \pm 0 \cdot 8 \\
r=23\end{array}$ & $5 \cdot 5 \pm 0 \cdot 5$ & $\begin{array}{l}6 \cdot 4 \pm 1 \cdot 1^{*} \\
r=17\end{array}$ & $5 \cdot 7 \pm 0 \cdot 5$ & $\begin{array}{l}7 \cdot 1 \pm 1 \cdot 9 * \\
\mathrm{r}=21\end{array}$ & $5 \cdot 7 \pm 0 \cdot 6$ \\
\hline
\end{tabular}

*Indicates latencies statistically prolonged compared to the control values (Students $t$ test, p $<0.01$ ).

" $r$ " denotes number of responses included in any one group. 
(Students $t$ test $\mathrm{p}<0 \cdot 01$ ); no change was seen in the group with a diagnosis of possible MS. In patients with a diagnosis of probable MS only N20 was attenuated while in patients with a diagnosis of definite MS both N14 and N20 were reduced.

Response latencies and conduction times are shown in table 2 . N14, when present, rarely was of increased latency while N20 was increased only in patients with a diagnosis of definite MS. The central conduction time N14-N20 was prolonged both in patients with a diagnosis of probable and definite MS, suggesting that the conduction time was a more sensitive measure than response latencies.

RESPONSE CHARACTERISTICS Table 3 shows the most frequent changes of N14 and N20 observed. Since the normal configuration of the cervical and the later components in the cortical evoked response varied considerably, no attempts were made to classify the morphology of the responses. The lower amplitude limit of I $\mu \mathrm{V}$ was chosen since this was the lowest value found in the control groups. Well-defined N14 and N20 with amplitudes as low as $0.2 \mu \mathrm{V}$, however, were frequently observed in patients with multiple sclerosis. The data in table 3 confirmed that the number of pathological responses increased with the certainty of the clinical diagnosis.

AFFERENT CONDUCTION TIMES To examine whether estimation of the afferent conduction times could yield evidence for a slowing of the central con-

Table 3 Number of evoked responses absent, below $1 \mu V$ or with a significantly delayed latency in each patient group

\begin{tabular}{|c|c|c|c|c|c|c|}
\hline \multirow[t]{3}{*}{ Diagnosis $n$} & \multicolumn{4}{|c|}{ Response amplitude } & \multirow{2}{*}{\multicolumn{2}{|c|}{$\begin{array}{l}\text { Latency } \\
\text { increased } \\
>2.5 S D\end{array}$}} \\
\hline & \multicolumn{2}{|c|}{$N 14$} & \multicolumn{2}{|l|}{$N 20$} & & \\
\hline & Absent & $I<\mu V$ & Absent & $I<\mu V$ & $\overline{N 14}$ & $N 20$ \\
\hline $\left.\begin{array}{l}\text { Suspected } \\
\text { possible }\end{array}\right\} 12$ & $\mathbf{0}$ & $\mathbf{0}$ & 1 & 4 & 0 & 0 \\
\hline $\begin{array}{ll}\text { Probable } & 12 \\
\text { Definite } & 20\end{array}$ & $\begin{array}{l}1 \\
9\end{array}$ & $\begin{array}{l}2 \\
4\end{array}$ & $\begin{array}{l}4 \\
8\end{array}$ & $\begin{array}{l}5 \\
8\end{array}$ & $\begin{array}{l}0 \\
1\end{array}$ & $\begin{array}{l}1 \\
6\end{array}$ \\
\hline
\end{tabular}

duction time in patients with normal or small changes in $\mathrm{N} 14$ and N20, the responses were classified as being either normal, inconclusive or definitely pathological. Absence of a response or a statistically significant increase in response latency were considered pathological. A welldefined cervical or cortical response with unusual configuration or a slight amplitude attenuation $(0.7-0.9 \mu \mathrm{V})$ of $\mathrm{N} 14$ or $\mathrm{N} 20$ in an otherwise normal response were considered inconclusive changes.

A: Suspected and possible MS: (Table 4) The changes in the evoked responses were inconclusive in two of the five patients with suspected MS. Estimation of afferent conduction times added no further information. In the seven patients with possible multiple sclerosis the responses were pathological in only one patient in whom N20 was absent unilaterally. Estimation of the afferent conduction times revealed three

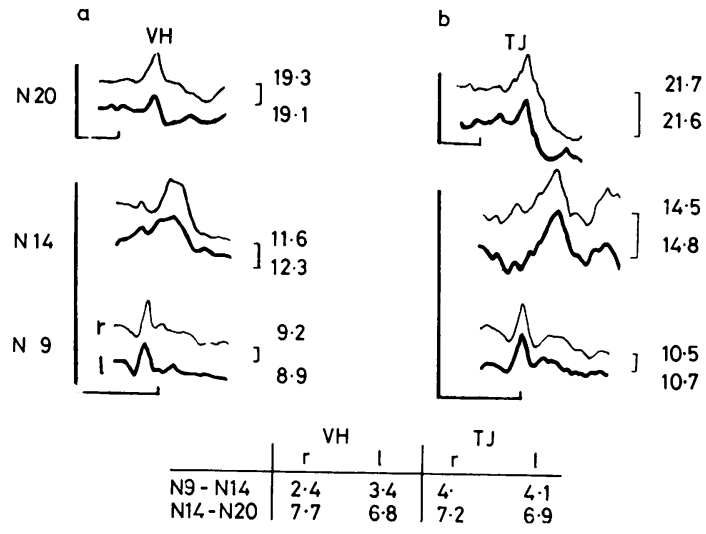

Fig 1 Examples of normal evoked responses and prolonged central conduction times in two patients with possible multiple sclerosis. Potentials evoked by stimulation of the right median nerve always uppermost. Calibration bars represent $2.5 \mu \mathrm{V}$ and time scale $10 \mathrm{~ms}$. Note different time scale for the scalp records. Peak latencies are denoted by numbers to the right of each record. Conduction times for each patient are given in the table below records

Table 4 Evoked response characteristics and afferent conduction times in patients with suspected $(A)$ and possible (B) multiple sclerosis

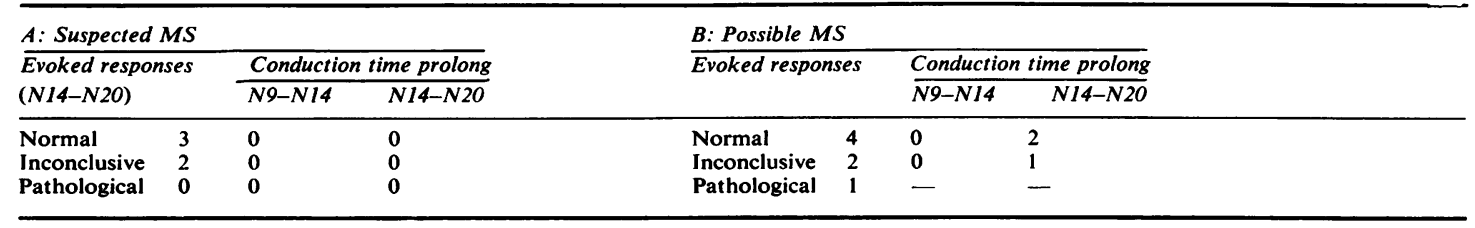


more patients with a significant slowing of the N14-N20 conduction time. In two. of these patients the evoked cervical and cortical responses were normal (fig 1A and B).

$B$ : Probable and definite $M S$ : (Table 5) Although the number of pathological responses was much greater in these groups, there were many normal or inconclusive responses (six and seven patients respectively in each group). Estimation of the afferent conduction times increased the number of pathological responses. N14-N20 was prolonged in three patients with probable MS and in five patients with a definite diagnosis. When conduction time was included, the test results were definitely pathological in $67 \%$ and $90 \%$ of patients with probable and definite multiple sclerosis respectively. A significant prolongation of N14-N20 also was present in one patient with a diagnosis of definite MS and normal evoked response properties. Examples of the variations of the evoked responses in these two groups are illustrated in fig $2 \mathrm{~A}-\mathrm{D}$.

\section{Discussion}

Attenuation of N14 and N20 was frequent in patients with probable and definite MS, while no reduction was present in the earlier stages of the disease. The results failed to reveal any latency shift of N14, while a delayed N20 was present in patients with definite MS only. A prolonged central conduction time was present both in the groups with a probable and definite diagnosis suggesting that estimation of the central conduction time was a more sensitive method of detecting delayed central impulse propagation than the latencies of either N14 or N20. As emphasised previously ${ }^{12} 13$ the latency of N20 mainly is determined by the conduction time in the peripheral nerve and less by the conduction times in the two central segments tested with the present recording technique.

The number of patients showing changes in the cervical or cortical evoked responses has varied in the different studies published. ${ }^{15-9}$

Table 5 Evoked response characteristics and afferent conduction times in patients with probable $(A)$ and definite $(B)$ multiple sclerosis

\begin{tabular}{|c|c|c|c|c|c|c|c|}
\hline \multicolumn{4}{|c|}{ A: Probable MS } & \multicolumn{4}{|c|}{$B:$ Definite $M S$} \\
\hline \multirow{2}{*}{\multicolumn{2}{|c|}{$\begin{array}{c}\text { Evoked responses } \\
n\end{array}$}} & \multicolumn{2}{|c|}{ Conduction time prolong } & \multicolumn{2}{|c|}{ Evoked responses } & \multicolumn{2}{|c|}{ Conduction time prolong } \\
\hline & & $\overline{N 9-N 14}$ & $\overline{N 14-N 20}$ & & $n$ & $N 9-N 14$ & N14-N10 \\
\hline Normal & 1 & 0 & 0 & Normal & 2 & 0 & 1 \\
\hline Inconclusive & 5 & 0 & 2 & Inconclusive & 5 & 0 & 4 \\
\hline Pathological & 6 & - & - & Pathological & 13 & - & - \\
\hline
\end{tabular}

Sum pathological tests

$67 \%$

$90 \%$

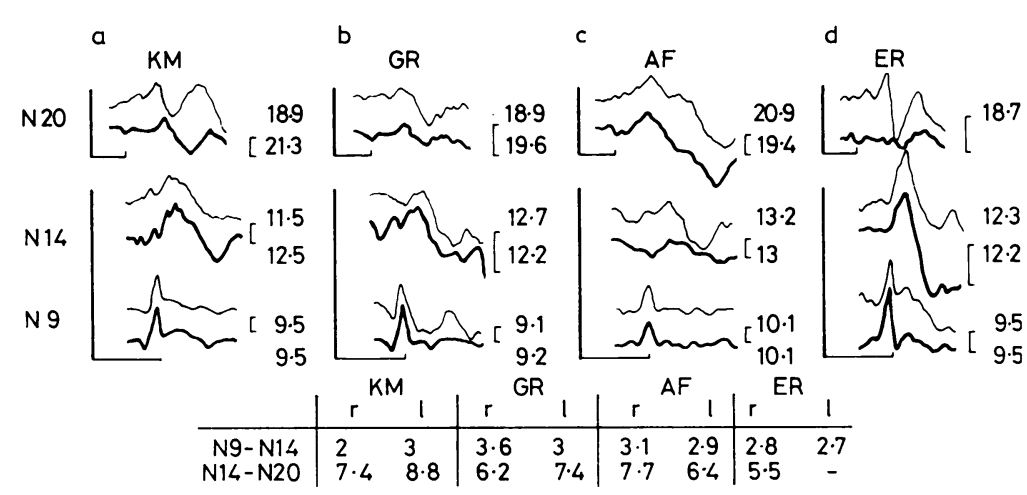

Fig 2 Examples of evoked responses and prolonged central conduction times in patients with probable and definite MS. Peak latencies are given to the right of each record, calibration bars represent $2 \cdot 5 \mu \mathrm{V}$ and time scale $10 \mathrm{~ms}$. Note different time scale for scalp records. Conduction times for any one patient are given in the table below records. A: Normal evoked responses except for an unusually large latency difference of $\mathrm{N} 20$ bilaterally. B: Well preserved evoked responses but low amplitudes of N14 and N2O. $C$ : Well preserved evoked responses but an abnormally wide N20.D: Normal evoked responses except for N20 which was absent unilaterally. 
When the electrophysiological diagnosis was based on changes in response properties, the present data showed that the SEP test was definitely pathological in $14 \%, 50 \%$ and $65 \%$ of the patients with possible, probable and definite multiple sclerosis respectively. The number of pathological tests thus were somewhat lower than previously reported, ${ }^{5} 89$ probably due to the response classification used in the present study.

When a prolonged conduction time was included as a criterion of a central lesion, the number of conclusive pathological tests increased in all groups. An exception was the group of five patients with suspected multiple sclerosis, none of whom had a prolonged central conduction time. This may suggest that these patients were in a very early phase of the disease prior to any detectable changes in the central conduction times. (There is also the possibility of a misdiagnosis in this group.)

Severe derangements or abolition of the cervical or cortical evoked responses probably reflects relatively large areas of demyelination in the afferent pathways since conduction block is the ultimate result of demyelination. The first change in multiple sclerosis probably is a local segmental demyelination merely resulting in a slowing of impulse propagation of the injured area. ${ }^{20}$ Although few patients were examined, the fact that two out of four patients with possible MS had a prolonged central conduction time as the only pathological finding supports this assumption and emphasises that estimation of central conduction time is of particular diagnostic value in the early phase of the disease.

The SEP test is of less value in patients with a probable or a definite clinical diagnosis. The present data, however, indicate that estimation of the central conduction time also in these groups increased the diagnostic strength of the SEP test by reducing the number of inconclusive results.

Changes in somatosensory evoked responses have previously been compared to neurological symptoms as well as to relapses and remissions of the disease. ${ }^{1}$ 6-9 The results are somewhat confusing since some have reported a clear relation between the SEP results and clinical relapses and remissions, ${ }^{7}$ while others have not found such a correlation. ${ }^{6}$ The fact that patients with impaired vibration and position sense may have a normal somatosensory evoked response is also surprising. ${ }^{17-9}$ Although no attempts were made in the present study to correlate the results with the clinical findings, it is not unlikely that the more sensitive conduction time rather than changes in evoked response characteristics may resolve some of these problems.

Evaluation of the central conduction times is based on a number of approximations. Firstly, $\mathrm{N} 14$ and N20 are synaptic potentials. The peak to peak time defined as the central conduction times thus also includes the time needed for generation of the synaptic potential. Secondly, the exact generator site of N14 is still debated. Most data11 1415 point to the medulla caudal to the dorsal column nuclei as a probable generator site. The N9-N14 conduction time includes impulse propagation in the proximal plexus and dorsal roots; patients with cervical radiculopathy had a prolonged N9-N14 conduction time. ${ }^{13}$ Evidence further exists that N9-N14 conduction time in addition comprise a part of the central afferent pathway, ${ }^{11} 1215$ probably the dorsal column. The N14-N20 conduction time represents a genuine central conduction time and the present data suggest that a slowing of impulse propagation in MS patients affects this segment of the afferent system rather than the segment involved in N9-N14 conduction time. Whether this indicates an unequal liability to MS in the two parts of the afferent systems or merely represents a quantitative effect reflecting the different lengths of the segments involved has yet to be determined.

\section{References}

1 Baker JB, Larsson SJ, Sances A, White PT. Evoked potentials as an aid to the diagnosis of multiple sclerosis. Neurology 1968; 18:286.

2 Desmedt JE, Noël P. Average cerebral evoked potentials in evaluation of lesions in the sensory nerves and of the central somatosensory pathway. In: Desmedt JE, ed. Electromyography and Clinical Neurophysiology, Volume II. Basel: S Karger, 1973: 352-71.

3 Eisen A, Nudleman K. F-wave and cervical somatosensory response conduction from the seventh cervical spinous process to cortex in multiple sclerosis. Canad J Neurol Sci 1978; 5: 289-95.

4 Halliday AM. The effect of lesions of the afferent pathways and cerebrum on the somatosensory response. In: Remond A, ed. Handbook of Electroencephal Clin Neurophysiol. Volume 8. Amsterdam: Elsevier Publishing Company, 1975: 129-37.

5 Mastaglia FL, Black JL, Collins DWK. Visual and spinal evoked potentials in diagnosis of multiple sclerosis. Br Med J 1976; 3:732.

6 Matthews WB, Small DG. Serial recording of visual and somatosensory evoked potentials in 
multiple sclerosis. J Neurol Sci 1979; 40:11-21.

7 Namerow NS. Somatosensory evoked responses in multiple sclerosis patients with varying sensory loss. Neurology 1968; 18:1197-204.

8 Small DG, Matthews WB, Small M. The cervical somatosensory evoked potential in the diagnosis of multiple sclerosis. J Neurol Sci 1978; 35: 211-24.

9 Trojaborg W, Petersen E. Visual and somatosensory evoked cortical potentials in multiple sclerosis. J Neurol Neurosurg Psychiatry 1979; 42:323-30.

10 Cracco RQ, Bickford RG. Somatomotor and somatosensory evoked responses. Arch Neurol 1968; 18:52-68.

11 El-Negamy E, Sedgwick M. Properties of a spinal somatosensory evoked potential in man. $J$ Neurol Neurosurg Psychiatry 1978; 41:762-8.

12 Ganes T. A study of peripheral, cervical and cortical evoked potentials and afferent conduction times in the somatosensory pathway. Electroencephal Clin Neurophysiol 1980; in press.

13 Ganes T. Somatosensory conduction times and peripheral, cervical and cortical evoked potentials in patients with cervical spondylosis. $J$
Neurol Neurosurg Psychiatry 1980; in press.

14 Hume AL, Cant BR. Conduction time in central somatosensory pathways in man. Electroencephal Clin Neurophysiol 1978; 45:361-75.

15 Jones SJ. Short latency potentials recorded from the neck and scalp following median nerve stimulation in man. Electroencephal Clin Neurophysiol 1977; 43:853-63.

16 Hume AL, Cant BR, Shaw NA. Central somatosensory conduction time in comatose patients. Ann Neurol 1978; 5:379-84.

17 Symon L, Hargadine J, Zawirski M, Branston N. Central conduction time as an index of ischaemia in subarachnoid haemorrhage. J Neurol Sci 1979; 44:95-103.

18 McAlpine D, Lumsden CE, Acheson ED Multiple sclerosis, a reappraisal. Edinburgh and London: Churchill Livingstone, 1972.

19 McDonald WI, Halliday AM. Diagnosis and classification of multiple sclerosis. Br Med Bull 1977; 33:4-8.

20 Halliday AM, McDonald WI. Pathophysiology of demyelinating disease. $\mathrm{Br}$ Med Bull 1977; 33: 21-7. 